\title{
On the imperative of thinking through the ethical, health equity, and social justice possibilities and limits of digital technologies in public health
}

\author{
Oralia Gómez-Ramírez $^{1,2,3}$ (D) Ihoghosa lyamu ${ }^{2} \cdot$ Aidan Ablona $^{1} \cdot$ Sarah Watt $^{1} \cdot$ Alice X. T. Xu $^{2} \cdot$ Hsiu-Ju Chang ${ }^{1}$. \\ Mark Gilbert ${ }^{1,2}$
}

Received: 28 August 2020 / Accepted: 28 January 2021 / Published online: 16 March 2021

(C) The Canadian Public Health Association 2021

\begin{abstract}
The COVID-19 pandemic has demonstrated both the positive and negative use, usefulness, and impact of digital technologies in public health. Digitalization can help advance and sustain the core functions of public health, including health promotion and prevention, epidemiological surveillance, and response to emergent health issues. Digital technologies are thus - in some areas of public discourse - presented as being both necessary and inevitable requirements to address routine and emergency public health issues. However, the circumstances, ways, and extent to which they apply remain a subject of critical reflection and empirical investigation. In this commentary, we argue that we must think through the use of digital technologies in public health and that their usefulness must be assessed in relation to their short- and long-term ethical, health equity, and social justice implications. Neither a sense of digital technological optimism and determinism nor the demands of addressing pressing public health issues should override critical assessment before development and implementation. The urgency of addressing public health emergencies such as the ongoing COVID-19 pandemic requires prompt and effective action, including action facilitated by digital technologies. Nevertheless, a sense of urgency cannot be an excuse or a substitute for a critical assessment of the tools employed.
\end{abstract}

\section{Résumé}

La pandémie de COVID-19 a montré les aspects positifs et négatifs de l'utilisation, de l'utilité et de l'impact des technologies numériques en santé publique. La numérisation peut contribuer à promouvoir et à soutenir les fonctions de base de la santé publique, dont la promotion de la santé, la prévention, la surveillance épidémiologique et la riposte aux nouvelles crises sanitaires. Les technologies numériques sont donc-dans certaines parties du discours publicprésentées comme étant à la fois nécessaires et inévitables pour résoudre les problèmes de santé publique ordinaires ou urgents. Par contre, les circonstances, les moyens et la mesure dans laquelle elles s'appliquent font encore l'objet d'une réflexion critique et d'une investigation empirique. Dans ce commentaire, nous faisons valoir qu'il faut bien réfléchir à l'utilisation des technologies numériques en santé publique, et que leur utilité doit être analysée par rapport à leurs conséquences à court et à long terme sur l'éthique, l'équité en santé et la justice sociale. Ni les sentiments d'optimisme et de déterminisme à l'égard des technologies numériques, ni la nécessité de résoudre les problèmes de santé publique pressants ne devraient prendre le dessus sur l'analyse critique avant leur développement et leur mise en œuvre. L'urgence de résoudre des crises sanitaires comme la pandémie actuelle de COVID-19 nécessite une action rapide et efficace, et cette action peut être facilitée par les technologies numériques. Néanmoins, le sentiment d'urgence ne doit pas être une excuse et ne peut pas remplacer une analyse critique des outils employés.

Oralia Gómez-Ramírez

oraliagr@alumni.ubc.ca

1 British Columbia Centre for Disease Control, 655 West 12th Avenue, Vancouver, BC V5Z 4R4, Canada
2 School of Population and Public Health, University of British Columbia, Vancouver, BC, Canada

3 CIHR Canadian HIV Trials Network, Vancouver, BC, Canada 
Keywords Public health $\cdot$ Digital technologies $\cdot$ Social justice $\cdot$ Ethics $\cdot$ Health equity $\cdot$ Digital health $\cdot$ Emergency response

Mots-clés Santé publique $\cdot$ technologies numériques $\cdot$ justice sociale $\cdot$ éthique $\cdot$ équité en santé $\cdot$ santé numérique $\cdot$ intervention d'urgence

\section{Introduction}

Dramatic and rapid digital technological change in healthcare and public health has occurred in the months following the World Health Organization's pandemic declaration for the COVID-19 outbreak. Responses to the pandemic have demonstrated the utility and effectiveness of digital technologies (DTs) in core public health functions of epidemiological surveillance and emergency management and response (e.g., Global Public Health Intelligence Network). Simultaneously, public-facing DTs such as web-based symptom self-checkers or Bluetooth-enabled proximity notification systems have been introduced to guide user actions based on the latest testing guidelines and notify users of possible exposure.

The application of a wide range of DTs, such as big data for surveillance and epidemiology, social media for health promotion, or artificial intelligence for emergency preparedness and response, is not new in public health (Odone et al. 2019). However, their uncritical use can also entail significant shortcomings, including widening existing health inequalities by overlooking end-users' access and capacity to engage with DTs (Azzopardi-Muscat and Sørensen 2019) or excluding certain groups (including healthcare providers) from novel digital health ecosystems (Lupton 2017). These disparityexacerbating effects can occur when intended end-users cannot utilize DTs to their maximum benefit. Disparities may also be exacerbated when public health leaders neglect to anticipate how internal DTs can perpetuate socio-economic inequities, or when practitioners are precluded from employing DTs to inform action due to insufficient technical expertise, infrastructure, or funding to access these DTs. Additionally, undiscerning usage of DTs can fail to consider the contextual power dynamics in which they operate (Sinha and Schryer-Roy 2018), reflect discriminatory racial and gender value judgements (Smith et al. 2020), and reinforce the social gradients of health (Crawford and Serhal 2020). The COVID-19 pandemic offers a stark reminder of the benefits, the limitations, and the imperative of thinking through DTs as they become more ubiquitous in public health (Kofler and Baylis 2020).

Using COVID-19 as an example, but referring to public health broadly, we argue that DTs' usefulness must be assessed in relation to their short- and long-term impacts on ethical, health equity, and social justice considerations. The critical assessment of DTs should not be overridden by a sense of digital technological optimism (the belief that DTs can and will solve all issues), determinism (the notion that DTs are the one and only way forward), nor the demands of addressing pressing public health issues. Despite pressure on public health practitioners to expedite DT development and implementation in response to public health emergencies like COVID-19, we posit that these assessments remain crucial and feasible before introducing DTs and as an ongoing practice.

We offer a set of guiding considerations for public health officials, policymakers, and researchers to think through the use, usefulness, and impact of DTs in public health (Table 1). Rather than being exhaustive or prescriptive, or focusing solely on responding to emergencies through digital means, we aim to stimulate purposeful reflection and to provide an orientation to the interrelated, overlapping, and co-constitutive ethical, health equity, and social justice issues that must be considered more broadly in digital public health. While these issues should be explored in more detail for each DT, we summarize them here to incentivize further debate and research.

\section{Ethics}

Thinking through ethical issues involves distinguishing and weighing the values that serve to prioritize and justify public health actions. Discussions before COVID-19 focused on acknowledging the mounting ethical implications arising with DTs, such as preserving data privacy and security, misusing information, and the consequent withdrawal of target endusers from participating in potentially beneficial public health interventions (Gilbert et al. 2016; Marckmann 2020). The primary attention to the ethics of digital interventions as publicfacing tools for end-users, however, somewhat eclipsed scrutiny of DTs as means within public health shaping the interests of various interest stakeholders (Brall et al. 2019).

The COVID-19 pandemic has refocused these discussions. For example, Morley et al. (2020) argue that the hasty roll-out of exposure tracing applications can preclude ethical considerations and involve unnecessary financial and public trust costs. Barton et al. (2020) condemn how concealment and competition can engender inequalities in the opportunity to benefit from existing big data and artificial intelligence tools. Martinez-Martin et al. (2020) question traditional ethics models focused on individuals' privacy protection and software output features, in a time when private tech companies 
Table 1 Considerations for public health officials, policymakers, and researchers to think through digital technologies in public health ${ }^{\mathrm{i}}$

Domain Guiding considerations ${ }^{\text {ii }}$

1) Thinking through ethics

Justification

Impact

Transparency

2) Thinking through health equity Benefits

Burdens

Root causes

Upstream

action

3) Thinking through social justice Context

Profit distribution

Misuse

Public goods
Have public health officials, policymakers, and/or researchers (hereafter "stakeholders") considered and deliberated the ethical justification of the digital technology (DT)?

E.g., Developing and/or using a DT should be evidence-and/or needs-based. The DT being used should achieve an explicit and unambiguous public health goal or function, rather than a technological end on its own.

Have stakeholders considered the potential impact of developing and/or using a specific DT on health equity and social justice, including benefits, limitations, and misuses?

E.g., An evaluation plan of the short- and long-term implications should be developed when using a DT for public health goals and/or functions, as well as a concrete and feasible plan to ensure rapid and effective de-implementation when the DT engenders more unintended health equity and social justice harms than benefits.

Have stakeholders been transparent about the critical assessment process of identifying both potential (short- and long-term) benefits and limitations of DTs?

E.g., The process should be open and inclusive of all relevant public health stakeholders and members of society. Transparency also entails meaningfully including impacted populations in the decision-making.

Have stakeholders considered the benefits of developing and/or using the DT for addressing health inequities? E.g., The analyses of benefits should consider whether, when, for whom, and under which circumstances the internal and/or public-facing DT can equitably benefit populations and countries.

Have stakeholders considered the burdens introduced by the development and implementation of the DT? E.g., Burdens must be both justifiable and distributed equitably.

Have stakeholders considered the way and extent to which developing and/or using a given DT can help both make visible and address root causes of population health inequities?

E.g., Ideally, a DT should purposefully be developed and implemented to help address the root causes of inequities in health.

Have stakeholders considered the way and extent to which the development and use of a DT can enable action on the health-system and socio-economic structural factors shaping the uneven distribution of population-health outcomes?

E.g., Ideally, a DT should purposefully be developed and implemented to help enable upstream (vs. downstream) action to foster public health.

Have stakeholders learned about and carefully reflected on the broader socio-political, economic, ecological, historical context in which the DT is being developed and applied?

E.g., Public health practice has, intentionally and unintentionally, affected certain communities disproportionately (e.g., Reverby (2009) recounts the Tuskegee study by which African-Americans and Guatemalans were left untreated for syphilis; Turpel-Lafond (2020) uncovers how the COVID-19 public health emergency response has amplified racism and structural vulnerabilities and disproportionately impacted Indigenous people in Canada). Given such past and present histories, the local and global context in which new DTs in public health are implemented should be front and centre in considering the implications of these technologies.

Have stakeholders considered how the people who contributed to creating and implementing the DT, including by providing their health data, will be fairly compensated? If financial profits are to be made from the development and use of DTs in public health, have stakeholders considered who will receive the profit and how it can ultimately be fairly redistributed to benefit communities and population health?

E.g., Given the increasing participation of corporate, non-state actors in creating and implementing DTs and in public health more broadly, direct and/or indirect forms of equitable compensation and profit redistribution should be devised.

Have stakeholders developed a concrete, feasible, and transparent plan to prevent the secondary use and misuse of the DT for purposes beyond the goals and functions of population and public health?

E.g., Potential redirection of the data or DT use for corporations' profit, political gain, government surveillance, privacy erosion, or social control, rather than public health purposes, should be prevented.

Have stakeholders considered whether the DT can help advance public health as a public good rather than as a commodity?

E.g., The foundational spirit of public health of advancing the health of the people and that population health is a public good should prevail and be safeguarded.

Notes: ${ }^{\text {i }}$ The list of guiding considerations stems from five collective discussions held by the authors between April 14 and June 9, 2020 , based on review and discussion of selected popular and academic articles and current news affairs as provocations and opportunities to make sense of the unfolding COVID-19 pandemic. ${ }^{\text {ii }}$ These guiding questions are not meant to be exhaustive or all-encompassing; each DT used in public health (e.g., genomics, big data, artificial intelligence, distributed ledger technologies, drones, robotics, smartphone apps, web-based applications, social media, wearables and sensors, virtual and augmented reality, and telehealth) will require a thoughtful critical assessment to determine the application and balance of each of the more specific realms. The examples are meant to provide a sense of direction about what would fail or succeed in critically assessing ethical, health equity, and social justice issues in digital public health. Significantly, ethical, health equity, and social justice issues are not isolated from each other. Still, the analytical distinction may help bring to the fore issues comprising each of these realms that might otherwise get missed from critical consideration if the domains are collapsed 
are leading the production of digital tools in the absence of a robust public health framework.

Moving forward, the long-standing ethical commitments of justification, impact, and transparency must be honoured. Evidence- and needs-based justifications (Zeeb et al. 2020) are necessary to demonstrate that DTs are instrumental tools for unambiguous public health goals and functions rather than technological ends. Furthermore, transparent public discussions about whether, when, for whom, and under which circumstances to use internal and public-facing DTs in public health must involve all stakeholders, including those providing the data behind many DTs.

\section{Health equity}

Thinking through health equity involves identifying and acting on the root causes of the uneven distribution of health-related burdens and outcomes. Earlier discussions about health equity in digital public health considered digitalization as a tool to address existing inequities and emphasized literacy as critical for access, uptake, and use of DTs (Azzopardi-Muscat and Sørensen 2019). However, these considerations have predominantly focused on end-users within a limited range of DTs, such as internet- and cellphone-based public health programs. Considerations about the ways and extent to which other DTs (e.g., big data or artificial intelligence) address health equity issues are evolving (Chauvin et al. 2016).

The COVID-19 pandemic has brought renewed attention to the urgency of using a health equity lens in reflecting on digitalization in public health. For example, Crawford and Serhal (2020) suggest the mainstreaming of digital technological innovations cannot come at the expense of inadvertently reinforcing the socio-economic gradients in health. Similarly, the country-level COVID-19 response accounts by Shadmi et al. (2020) draw attention to the uneven distribution of national and inter-provincial response resources and capacities (including DTs) that have led to dramatic health disparity outcomes across and within countries and populations.

Thus, the use, usefulness, and impact of DTs in public health should involve, at least, asking whether the short- and long-term benefits and burdens are equally distributed across socio-demographic groups and countries. Similarly, developers and implementers must ask how and to what extent DTs address the root causes of existing health inequities and enable upstream action for health equity.

\section{Social justice}

Thinking through social justice involves articulating powersensitive analyses that illuminate and address existing forms of societal oppression and injustice. Discussions related to the regulation and governance of digitalization (Ricciardi et al. 2019) and explicit consideration to the challenges faced by practitioners tasked with using DTs in public health (Jackson et al. 2019) garnered interest before the COVID-19 pandemic. However, an extensive and detailed discussion of social justice in the context of DTs in public health-unlike ethics and health equity-is still materializing.

With COVID-19, debates about the fair distribution of financial, social, and environmental burdens and advantages of new DTs are at an all-time high. Kofler and Baylis (2020) suggest that introducing novel tools (e.g., "immunity passports") without forethought to their broader implications can undermine human rights and privacy, engender novel forms of social stratification and scrutiny, and, ultimately, detract attention from established and effective public health strategies (e.g., testing, contact tracing, isolating) and ensuring global vaccine distribution.

Given this background, assessing DTs in public health using an anti-oppression lens must consider context, profit distribution, misuse, and public goods. One must consider the local and global context (socio-political, economic, ecological, and historical) in which DTs are developed and applied. Likewise, fair distribution of financial profits among contributors to the development and implementation of DTs, including those providing health data, must be considered. Redistribution may occur directly through equitable compensation or indirectly through raising revenue for public health programs. In considering revenue generation from DTs, the role of corporate, non-state interests in their implementation should be assessed (French et al. 2020; Green 2019). One must also reflect on secondary uses and potential misuses of the data collected through DTs, with explicit elucidation on how it could be erroneously redirected for corporations' profit, political gain, government surveillance, privacy erosion, or social control rather than public health purposes. Significantly, we must consider how DTs facilitate or hinder the pursuit of public health - as Nancy Krieger $(2015,591)$ states - as "a public good" rather than a commodity to be consumed. As such, careful reflection and empirical evaluation of the aforementioned social justice issues are required.

\section{Conclusion}

Public health experts must critically consider the use, usefulness, and impact of digital technologies in public health. Responding to public health emergencies like COVID-19 has thrown this ethical imperative into sharp relief. As old and new public health challenges confront experts to propose fair, effective, and expedient ways to address them, thoughtful considerations about ethics, health equity, and social justice cannot be sidestepped. Ultimately, digital tools in public health should only be the medium to the pursuit of public 
health goals and functions, rather than a technological endgoal on their own. Digitalization remains subsumed within public health purposes, and it remains the responsibility of public health professionals to pursue the public good. While DTs can help advance and sustain some core public health functions, their intensified and normalized use, as well as their potential benefits in times of public health emergency, cannot and should not be a substitute for thoughtful consideration of their broad-ranging repercussions.

Author contributions OGR and II conceived the idea of the commentary. OGR wrote and revised the manuscript. All authors participated in the discussions that led to this commentary and contributed substantially to the conception of this manuscript and the development of the guiding considerations. All authors provided critical revisions of the manuscript. All authors reviewed and provided final approval of the version to publish.

Funding The authors received no specific funding for this work. Postdoctoral funding for Gómez-Ramírez is provided by the Canadian Institutes of Health Research (Implementation Science Team Grant: FRN \#CTW-155387), the Canadian HIV Trials Network, and the Michael Smith Foundation for Health Research.

\section{Declarations}

Conflict of interest The authors declare no competing interests.

\section{References}

Azzopardi-Muscat, N., \& Sørensen, K. (2019). Towards an equitable digital public health era: Promoting equity through a health literacy perspective. European Journal of Public Health, 29, 13-17. https:// doi.org/10.1093/eurpub/ckz166.

Barton, C. M., Alberti, M., Ames, D., Atkinson, J.-A., Bales, J., Burke, E., Chen, M., Diallo, S. Y., Earn, D. J. D., Fath, B., Feng, Z., Gibbons, C., Hammond, R., Heffernan, J., Houser, H., Hovmand, P. S., Kopainsky, B., Mabry, P. L., Mair, C., Meier, P., Niles, R., Nosek, B., Osgood, N., Pierce, S., Polhill, J. G., Prosser, L., Robinson, E., Rosenzweig, C., Sankaran, S., Stange, K., \& Tucker, G. (2020). Call for transparency of COVID-19 models. Science, 368, 482-483. https://doi.org/10.1126/science.abb8637.

Brall, C., Schroder-Back, P., \& Maeckelberghe, E. (2019). Ethical aspects of digital health from a justice point of view. European Journal of Public Health, 29, 18-22. https://doi.org/10.1093/eurpub/ckz167.

Chauvin, J., Perera, Y., \& Clarke, M. (2016). Digital technologies for population health and health equity gains: The perspective of public health associations. Journal of Public Health Policy, 37, 232-248. https://doi.org/10.1057/s41271-016-0013-4.

Crawford, A., \& Serhal, E. (2020). Digital health equity and COVID-19: The innovation curve cannot reinforce the social gradient of health. Journal of Medical Internet Research, 22, e19361. https://doi.org/ 10.2196/19361.

French, M., Guta, A., Gagnon, M., Mykhalovskiy, E., Roberts, S. L., Goh, S., McClelland, A., \& McKelvey, F. (2020). Corporate contact tracing as a pandemic response. Critical Public Health. https://doi. org/10.1080/09581596.2020.1829549.

Gilbert, M., Swenson, L., Unger, D., Scheim, A., \& Grace, D. (2016). Need for robust and inclusive public health ethics review of the monitoring of HIV phylogenetic clusters for HIV prevention.
Lancet HIV, 3, e461. https://doi.org/10.1016/s2352-3018(16) 30156-4.

Green, J. (2019). Time to interrogate corporate interests in public health? Critical Public Health, 29, 257-259. https://doi.org/10.1080/ 09581596.2019 .1587886$.

Jackson, C., Gardy, J. L., Shadiloo, H. C., \& Silva, D. S. (2019). Trust and the ethical challenges in the use of whole genome sequencing for tuberculosis surveillance: A qualitative study of stakeholder perspectives. BMC Medical Ethics, 20, 43. https://doi.org/10.1186/ s12910-019-0380-z.

Kofler, N., \& Baylis, F. E. (2020). Ten reasons why immunity passports are a bad idea. Nature, 581, 379-381. https://doi.org/10.1038/ d41586-020-01451-0.

Krieger, N. (2015). Public health, embodied history, and social justice: Looking forward. International Journal of Health Services, 45 , 587-600. https://doi.org/10.1177/0020731415595549.

Lupton, D. (2017). Digital health now and in the future: Findings from a participatory design stakeholder workshop. Digital Health, 3, 1-17. https://doi.org/10.1177/2055207617740018.

Marckmann, G. (2020). Ethische Fragen von Digital Public Health [Ethical implications of digital public health]. Bundesgesundheitsblatt, Gesundheitsforschung, Gesundheitsschutz, 63, 199-205. https://doi. org/10.1007/s00103-019-03091-w.

Martinez-Martin, N., Wieten, S., Magnus, D., \& Cho, M. K. (2020). Digital contact tracing, privacy, and public health. Hastings Center Report, 50, 43-46. https://doi.org/10.1002/hast.1131.

Morley, J., Cowls, J., Taddeo, M., \& Floridi, L. (2020). Ethical guidelines for COVID-19 tracing apps. Nature, 582, 29-31. https://doi.org/10. 1038/d41586-020-01578-0.

Odone, A., Buttigieg, S., Ricciardi, W., Azzopardi-Muscat, N., \& Staines, A. (2019). Public health digitalization in Europe: EUPHA vision, action and role in digital public health. European Journal of Public Health, 29, 28-35. https://doi.org/10.1093/eurpub/ckz161.

Reverby, S. M. (2009). Examining Tuskegee: The infamous syphilis study and its legacy. Chapel Hill: University of North Carolina Press.

Ricciardi, W., Pita Barros, P., Bourek, A., Brouwer, W., Kelsey, T., \& Lehtonen, L. (2019). How to govern the digital transformation of health services. European Journal of Public Health, 29, 7-12. https://doi.org/10.1093/eurpub/ckz165.

Shadmi, E., Chen, Y., Dourado, I., Faran-Perach, I., Furler, J., Hangoma, P., Hanvoravongchai, P., Obando, C., Petrosyan, V., Rao, K. D., Ruano, A. L., Shi, L., de Souza, L. E., Spitzer-Shohat, S., Sturgiss, E., Suphanchaimat, R., Villar Uribe, M., \& Willems, S. (2020). Health equity and COVID-19: Global perspectives. International Journal for Equity in Health, 19, 104. https://doi.org/10.1186/ s12939-020-01218-z.

Sinha, C., \& Schryer-Roy, A.-M. (2018). Digital health, gender and health equity: Invisible imperatives. Journal of Public Health, 40, ii1-ii5. https://doi.org/10.1093/pubmed/fdy171.

Smith, M. J., Axler, R., Bean, S., Rudzicz, F., \& Shaw, J. (2020). Four equity considerations for the use of artificial intelligence in public health. Bulletin of the World Health Organization, 98, 290-292. https://doi.org/10.2471/blt.19.237503.

Turpel-Lafond, M. E. (2020). In plain sight: Addressing indigenousspecific racism and discrimination in B.C. health care. Addressing Racism Review Summary Report, British Columbia. https://engage. gov.bc.ca/app/uploads/sites/613/2020/11/In-Plain-Sight-SummaryReport.pdf. Accessed 13 Jan 2021.

Zeeb, H., Pigeot, I., \& Schüz, B. (2020). Digital Public Health - ein Überblick [Digital public health - an overview]. Bundesgesundheitsblatt, Gesundheitsforschung, Gesundheitsschutz, 63, 137-144. https://doi. org/10.1007/s00103-019-03078-7.

Publisher's note Springer Nature remains neutral with regard to jurisdictional claims in published maps and institutional affiliations. 